\title{
Respirology manpower in Canada - A report for the Canadian Thoracic Society Education Committee
}

\author{
Donald W Cockcroft MD FRCPC ${ }^{1}$, David Wensley MD FRCPC ${ }^{2}$ \\ ${ }^{1}$ Department of Medicine, Division of Respiratory Medicine, Royal University Hospital, \\ Saskatoon, Saskatchewan; ${ }^{2}$ Division of Critical Care, BC's Children's Hospital, Vancouver, \\ British Columbia
}

DW Cockcroft, D Wensley. Respirology manpower in Canada - A report for the Canadian Thoracic Society Education Committee. Can Respir J 2000;7(6):451-455.

A report on adult and pediatric respirology manpower in Canada was prepared from data supplied by the Royal College of Physicians and Surgeons of Canada (RCPSC), and from program directors (and other colleagues) at universities across Canada. The data support a significant deficiency of adult respirologists in Canada, which is estimated to be from $10 \%$, based on a 10-year-old outdated RCPSC recommendation, to $20 \%$, based on equalization with the 'best' province, to as high as $50 \%$, based on long waiting lists, particularly for respiratory sleep problems, and estimates obtained from academic centres across Canada. Although there are less data available for pediatric respirology, a similar approach suggests a $50 \%$ to $100 \%$ shortfall in pediatric respirologists. Output from Canadian training programs in adult and pediatric respirology is not likely to meet this need. We recommend that steps be taken urgently to provide sufficient resources for training adult and pediatric respirologists, and to ensure that funding is provided for subspecialist positions in the community.

Key Words: Adult respirology; Manpower; Pediatric respirology
Effectifs en pneumologie au Canada - Rapport du comité de formation de la Société canadienne de thoracologie

RÉSUMÉ : Un rapport sur les effectifs en pneumologie de l'adulte et de l'enfant au Canada a été préparé à partir des données fournies par le Collège royal des médecins et chirurgiens du Canada (CRMCC) et des directeurs de programmes (et autres collègues) des universités canadiennes. Ces données confirment l'importante pénurie de spécialistes en pneumologie de l'adulte au Canada, estimée être de $10 \%$, selon des données vieilles de dix ans trouvées dans les recommandations du CRMCC, à $20 \%$, en comparaison avec la «meilleure» province, et jusqu'à $50 \%$, si l'on se fie aux longues listes d'attente (particulièrement pour les problèmes respiratoires liés au sommeil) et aux estimations obtenues des établissements de formation du Canada. Bien que l'on ait des données moins complètes en pneumologie pédiatrique, la même approche donne à penser que la pénurie de pneumologues pédiatriques se situerait entre 50 et $100 \%$. Or, les effectifs fournis par les programmes de formation canadiens en pneumologie de l'adulte et de l'enfant risquent fort peu d'arriver à répondre à la demande. Nous recommandons donc des mesures urgentes pour obtenir des ressources suffisantes pour la formation de pneumologues œuvrant auprès des adultes et des enfants et pour assurer le financement de postes en sous-spécialité dans la communauté.
$\mathrm{T}$ This report was prepared for the Canadian Thoracic Society (CTS) Education Committee in the spring of 2000. The committee wished to have some objective data on respirology manpower in Canada on which to base future planning and recommendations regarding respiratory training and reentry into respiratory training in Canada. The subcommittee preparing this report included Dr Don Cockcroft for adult respirology and Dr David Wensley for pediatric respirology. 
TABLE 1

Distribution of adult respirologists by province, 2000

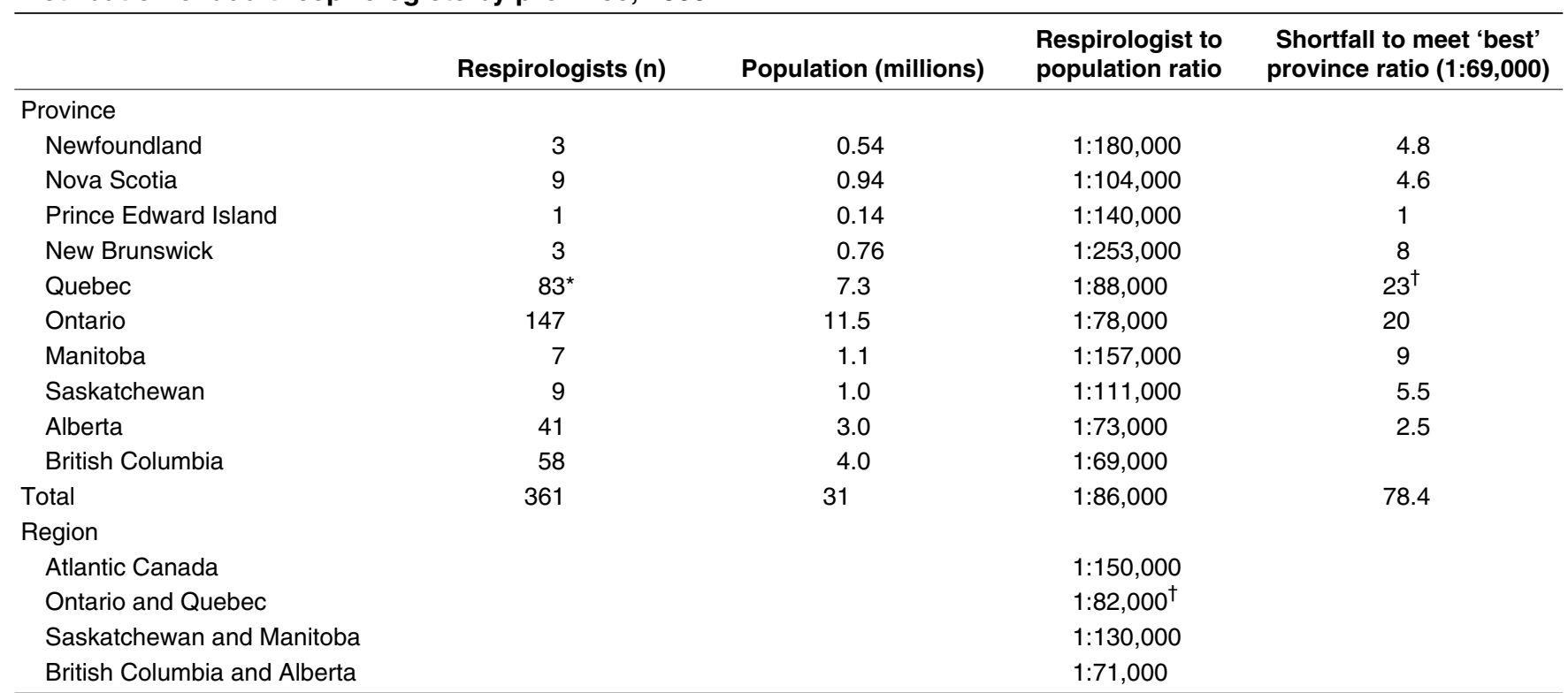

*Underestimated value because many Quebec respirologists were not captured by the Royal College of Physicians and Surgeons of Canada data banks; ${ }^{\dagger}$ Subject to error regarding the number of Quebec respirologists. Data from reference 1

The data used to compile the adult report came from the program directors of the 13 adult respirology programs, from the respiratory divisions at the remaining three Canadian medical schools, and from the Royal College of Physicians and Surgeons of Canada (RCPSC) (1-8).

The data used to create the pediatric report came from the Paediatrician Resource Planning Report (1997) (9), a recent survey of directors of training programs in pediatric respiratory medicine in July 2000 and the RCPSC (10).

\section{ADULT RESPIRATORY MANPOWER}

Current respirology manpower: In the year 2000, 361 physicians with Fellow of the Royal College of Physicians of Canada (FRCPC) certification in adult respiratory medicine in good standing with the RCPSC are residing in Canada (1). (For the rest of this report, they will be referred to as 'respirologists'). There are also 50 respirologists in good standing living outside Canada. The current population of Canada is slightly over $31,000,000$; the approximate ratio of respirologists per population in Canada is one to 86,000 . Currently, $55 \%$ of Canadian respirologists are under 45 years of age; $19.5 \%$ are women and $80.5 \%$ are men (1).

Regional distribution of respirologists by province is shown in Table 1. There are differences among regions across Canada, with British Columbia and Alberta having the greatest proportion of respirologists (one to 71,000), and Atlantic Canada, and Saskatchewan and Manitoba having the smallest per capita respirology communities (one to 130,000 and one to 150,000 , respectively). The number of respirologists in Quebec may be significantly underestimated because some Quebec respiratory medicine specialists are not registered with the RCPSC.

Over the past five years, the number of respirologists has increased at an average rate of 13 , or approximately $4 \%$, per year (2-6). The population has increased by slightly over $1 \%$ per year, leading to a real (per capita) increase in respirologists of less than $3 \%$ per year.

The following additional comments on the area of current adult respiratory manpower involve some speculation and may be subject to bias.

The number of respirologists on faculties or strongly affiliated with the 16 universities, including the 13 respiratory training programs, reaches a number (approximately 200) that exceeds one-half of the 361 respirologists in Canada. Many of these individuals have nonclinical commitments, particularly in the areas of teaching and research, and it is reasonable to assume that many of them represent a 0.5 fulltime equivalent (FTE [vis-à-vis clinical respirology]). Thus, this number - 361 - is an overestimate with regard to the number of FTE clinical respirologists.

A detailed 1995 workforce study (7) indicated that about $15 \%$ of respondents with FRCPC certification in adult respiratory medicine spend $50 \%$ or more of their time in another discipline, the two most common being critical care and general internal medicine. This further reduces the potential number of FTE clinical respirologists.

This may be balanced in part or in whole by the fact that approximately $4 \%$ of individuals with an FRCPC certification in general internal medicine report that they spend between $50 \%$ and $100 \%$ of their time practising respirology (7). Many of these individuals have training in respirology but no respirology FRCPC certification. This equates to approximately 100 or slightly more additional internists in Canada who are practising respirology and may, in large part, offset the overestimation of respirology manpower as noted above. It is likely that a substantial proportion of these individuals are 
older, trained respirologists who received and completed their training before or in the early stages of the recognition of respirology as a specialty and before the existence of the subspecialty 'respirology examination'.

As noted above, these data do not capture respirologists who are not registered with the RCPSC. This has been suggested as an issue, particularly in Quebec.

Respirology program output: The data presented herein are estimates based on responses from the program directors of the 13 respiratory training programs in Canada. An average of approximately 21 to 22 adult respirologists are being trained per year. An estimated $75 \%$ of these respirologists remain in Canada, indicating that 16 to 17 Canadian-trained respirologists are setting up practice in Canada every year. No data were available for non-Canadian-trained respirologists obtaining a Canadian FRCPC certification and setting up practice in Canada, but it is likely that this is a small number. Thus, there is an addition to the adult respirology workforce in Canada of about $4.5 \%$ per year. A $4 \%$ to $5 \%$ addition to the workforce per year would be unlikely to result in major gains in the respirology workforce and will likely do only slightly better than maintain the status quo. This is supported by the low growth in the number of respirologists (less than 3\% per year) between 1995 and 2000.

Manpower requirements: The 1988 recommendations from the RCSPC referred to a ratio of respirologists to population of one to 81,000 (8). These data appeared to be based on the total number of respirologists rather than clinical FTE respirologists alone. Accepting this latest, somewhat out-of-date recommendation, this would indicate a minimum current respirology shortfall in Canada of between 20 and 25. However, it is important to note that the 1988 recommendation was made before (or at the very beginning of) the recognition of both the importance and the high prevalence of sleep-disordered breathing.

Another way to address the adequacy of respirologists' numbers is to look at the average waiting time for consultation. The waiting time for a consultation showed extremely wide variability across Canada, ranging from as low as two weeks to as high as 12 weeks for a routine respiratory consultation, averaging seven or eight weeks for university-based consultations and four or five weeks for private practice consultations. These waiting periods are far from ideal but are not outrageous. By contrast, the waiting time for a sleep consultation averaged six months or longer - clearly an unacceptable delay.

A further way to assess manpower shortfall is to compare the regional and national shortfall in adult respirologists required to match the 'best' province ratio (British Columbia at one to 69,000$)$. These data are listed in the last column of Table 1; the estimate indicates a national shortfall of about 78 respirologists.

The uniform opinion of adult respiratory training programs across Canada is that there is a significant shortfall in respiratory manpower in Canada. Training program directors who chose to put a number on the ideal respirologist to population ratio gave a range between one to 30,000 and one to 80,000 , with an average ratio of one to 50,000 . The responder who recommended one to 80,0000 specified one FTE clinical respirologist per 80,000 population.

At the very least, the current data indicate a shortfall of $10 \%(n=35$ to 40$)$ in the number of respirologists in Canada. The most conservative recommendation coming from a program director in Canada (one FTE to 80,000 population) would require approximately a $20 \%$ increase in the number of respirologists, whereas the average recommendation coming from program directors (one to 50,000) would require a $50 \%$ to $60 \%$ increase in the number of respirologists. A $22 \%$ increase $(n=78)$ is required nationally to match the one to 69,000 ratio in the 'best' province.

\section{Summary: Adult respirology}

- The current number of respirologists in Canada $(n=361)$ is approximately one to 86,000 population.

- There is a wide regional variation in the per capita number of respirologists. This ranges from one to 71,000 in British Columbia and Alberta, to one to 82,000 in Quebec and Ontario, one to 130,000 in Saskatchewan and Manitoba, and one to 150,000 in Atlantic Canada.

- The amount of time spent by these individuals in activities other than clinical respirology (because of university commitments or commitments to other disciplines) is probably offset by the uncaptured number of respirologists practising without a Fellowship, or without current RCPSC registration.

- The one to 86,000 ratio of respirologists to population is below the 1988 recommendation of one to 81,000 - an outdated, presleep study recommendation.

- Over 50\% of respirology Fellowship holders are under 45 years of age; this may be partially offset by the older age of respirologists who do not have the RCPC Fellowship and who are uncaptured by available statistical databases.

- The rate of increase in FRCPC respirologists per capita in Canada between 1995 and 2000 is less than 3\% per year.

- The current retention of Canadian-trained respirologists in Canada equates to an addition of about $4 \%$ to 5\%, only adequate to maintain the status quo or slightly better.

- The average waiting time for a routine outpatient respiratory consultation ranges from just over a month for private practice respirology to just under two months for university-based respirology; this is not optimal and should be improved.

- The waiting time for respiratory sleep consultations is unacceptable at six months or longer.

- There is a universal perception in respiratory training programs that there is a large shortfall of adult respirology manpower in Canada. Conservative estimates would place this shortfall at between $10 \%$ and $22 \%(\mathrm{n}=36$ to 78$)$. 
TABLE 2

Distribution of pediatric respirologists by province, 2000

\begin{tabular}{|c|c|c|c|c|c|}
\hline \multirow[b]{2}{*}{ Province/region } & \multicolumn{2}{|c|}{ Respirologists } & \multirow[b]{2}{*}{ Population (millions) } & \multirow[b]{2}{*}{$\begin{array}{l}\text { Respirologist to } \\
\text { population ratio }\end{array}$} & \multirow[b]{2}{*}{$\begin{array}{l}\text { Shortfall to meet 'best' } \\
\text { province ratio }(1: 360,000)\end{array}$} \\
\hline & Total & $\begin{array}{l}\text { Clinical full-time } \\
\text { equivalents }\end{array}$ & & & \\
\hline Maritimes & 2 & 2 & 1.9 & $1: 950,000$ & 3.18 \\
\hline Quebec & 15 & 13 & 7.3 & $1: 500,000$ & 4.9 \\
\hline Ontario & 12 & 9 & 11.5 & $1: 950,000$ & 19.36 \\
\hline Alberta & 5 & 5 & 3.0 & $1: 750,000$ & 3.1 \\
\hline British Columbia & 2 & 1 & 4.0 & $1: 2,000,000$ & 8.9 \\
\hline Total & 41 & 33.5 & 31 & $1: 756,000$ & 41.63 \\
\hline
\end{tabular}

Data from reference 9

\section{PEDIATRIC RESPIRATORY MANPOWER}

Current respiratory manpower: In the year 2000, 24 physicians with a Certificate of Special Competence in Paediatric Respirology who are registered with the RCSPC are practising in Canada (10). Seventy-five per cent of these physicians are under 45 years of age, but because this certification was first granted in 1985, there are some physicians who are not registered but have established expertise. Fifty-four per cent of registered pediatric respirologists are men. Eight registered Fellows live outside Canada.

The regional distribution of physicians practising as pediatric respirologists by province is shown in Table 2 (9). Most pediatric respirologists are affiliated with major university teaching hospitals in Canada and often have nonclinical commitments, resulting in a significant reduction of clinical time. Thus, evaluating the number of physicians only results in a gross overestimation of available expertise. The Paediatrician Resource Planning Report (9) attempted to quantify this issue, and the data are presented in Table 2 as clinical FTEs.

No estimates of pediatric respiratory manpower in Canada or requirement recommendations existed before the Paediatrician Resource Planning Report in 1997 (9). All registered Fellows with Special Competence in Paediatric Respirology are pediatric specialists.

Pediatric respirology training programs: There are four recognized training programs in pediatric respirology and 15 trainees in these programs, 11 of whom are expected to remain in Canada. On average, four qualify each year. In general, these programs are in competition with other specialty and subspecialty resident programs within the university for trainee funding.

Manpower requirements: Respiratory disease is the most common reason for children to require hospitalization for acute illness, the most common cause of chronic disease in childhood, and one of the most common reasons for presenting to physicians in office visits. The vast majority of these acute and chronic problems are appropriately managed by pediatricians and family physicians. The role of the respiratory specialist is important in supporting pediatricians and family physicians, especially in severe or complex situations. Respiratory specialists also provide leadership, for example, in development of consensus guidelines, in all levels of education from medical students to continuing medical education, and in research. Respiratory specialists may have a special role in the management of some chronic disorders such as cystic fibrosis or chronic lung disease of prematurity, and the close involvement of respiratory specialists in cystic fibrosis has been associated with improvement in the outlook for children with this disease. Diagnostic bronchoscopy is now recognized as an appropriate activity for respiratory medicine specialists, and increasing complexity of patients (for example, with cancer) leads to an increasing demand for bronchial alveolar lavage and other investigations. Respiratory sleep disorders may affect $1 \%$ to $4 \%$ of the population. As in other respiratory disorders, many of these children receive excellent care from pediatricians and family physicians, but even the small percentage seen by respiratory medicine specialists places demands on the subspecialty.

The role of pediatric respirologists, pediatricians and family physicians in the care of individual children varies depending on many factors. Even though respiratory disorders are very common in childhood, the number of patients requiring care and, therefore, the number of specialists to provide care, is not large even in large cities. As shown in Table 2, even the most populous province in Canada can justify only 32 FTE specialists. Special arrangements must be made to support pediatric respirologists in small academic centres so that all children can have access to this expertise throughout Canada without placing unrealistic demands on the individual pediatric respiratory specialist. If support is not provided, there may be no opportunity for academic specialists to contribute locally to academic activities or to meet his or her own need for continuing medical education, or personal or family needs. Unless support is provided, it will be difficult to recruit and retain specialists.

The situation in Canada must be seen against the situation worldwide when there is a major shortage in the specialty. There are currently 55 positions being advertised for pediatric respirologists in the United States (11). 
Data (such as waiting lists, etc) are unavailable and of little relevance in estimating the shortfall in pediatric respirology manpower. However, assuming that all the provinces attain the 'best' ratio of pediatric respirologists to the population (one to 360,000) as outlined in Table 2, there is a shortfall of 42 physicians (Table 2). A $100 \%$ increase is required for all provinces to match the number of physicians in the province with the highest ratio of pediatric respirologists. Of significant concern in the Paediatrician Resource Planning Report (9) is the recognition that many provinces are training an insufficient number of pediatricians to meet the general pediatric requirements without considering pediatric subspecialty requirements. It will take over 10 years to train a sufficient number of pediatricians to meet the shortfall! It is crucial that steps be taken to deal with this crisis by providing sufficient training positions and funding for these, as well as funding for subspecialist positions in the community.

\section{Summary: Pediatric respirology}

- The ratio of pediatric respirologists in Canada is approximately one to 756,000 population or one to 925,000 FTE clinicians to population.

- There is a wide variation in the per capita ratio of pediatric respirologists, with one to 360,000 in the province with the highest ratio and one to $1,000,000$ in the province with the lowest ratio.

- The one to 360,000 ratio used to provide an estimate of the required number of pediatric respirologists nationally does not take into account the unmet needs to provide leadership in clinical care, education and research, as well as in new areas, such as pediatric sleep disorders. It also does not take into account the needs of subspecialists working in smaller populations who require a higher ratio to provide support for leadership activities.

- There are no data on waiting times for pediatric respiratory consultations, and pediatric sleep disorder clinics are not yet established in the majority of Canadian provinces.

- There is a $50 \%$ shortfall of pediatric respirologists, and the output of training programs of four graduates a year, assuming no attrition of current physicians, will not result in elimination of this shortfall in less than 10 years.

- Competition for funding for subspecialty training positions, inadequate funding of subspecialist positions in the community and the worldwide demands for this subspecialty will likely result in a reduction in the number of graduates available to practise in Canada in the future unless steps are taken to reverse these trends.

\section{CONCLUSION}

These data indicate a serious shortage in both adult and pediatric respirology manpower in Canada. Steps should be taken urgently to correct this important deficit.

ACKNOWLEDGEMENTS: We thank Jacquie Bramley for assisting in the preparation of this manuscript. We also thank Dr L-P Boulet, President, CTS; Dr G Ford, Chairperson, CTS Education Committee; Dr I Mitchell, Chairperson, CTS Paediatric Committee; the helpful staff at the Royal College of Physicians and Surgeons of Canada offices; and the respiratory program directors and other colleagues across the country whose helpful input contributed to this report.

\section{REFERENCES}

1. The Royal College of Physicians and Surgeons of Canada. Analysis of Specialty and Subspecialty Certification of Fellows in Good Standing, June 11, 2000. Ottawa: Royal College of Physicians and Surgeons of Canada, 2000.

2. The Royal College of Physicians and Surgeons of Canada. Analysis of Specialty and Subspecialty Certification of Fellows in Good Standing, January 25, 1999. Ottawa: Royal College of Physicians and Surgeons of Canada, 1999.

3. The Royal College of Physicians and Surgeons of Canada. Analysis of Specialty and Subspecialty Certification of Fellows in Good Standing, January 14, 1998. Ottawa: Royal College of Physicians and Surgeons of Canada, 1999.

4. The Royal College of Physicians and Surgeons of Canada. Fellows in Good Standing as of January 20, 1997. Ottawa: Royal College of Physicians and Surgeons of Canada, 1997.

5. The Royal College of Physicians and Surgeons of Canada. Fellows in Good Standing as of February 1996. Ottawa: Royal College of Physicians and Surgeons of Canada, 1996.

6. The Royal College of Physicians and Surgeons of Canada. Fellows in Good Standing as of February 1995. Ottawa: Royal College of Physicians and Surgeons of Canada, 1995.

7. Scully HE. 1995 RCPSC Specialty Physician Workforce Study. Ottawa: Royal College of Physicians and Surgeons of Canada, 1995.

8. Low JA. National Specialty Physician Review. Ottawa: Royal College of Physicians and Surgeons of Canada, 1988.

9. Hall JG, Melton P. Facts and Figures Please: Paediatrician Resource Planning. The 11th Ross Conference on Paediatrics: Child and Youth Health Care in the 21st Century. Mississauga, April 10 to 13, 1997.

10. The Royal College of Physicians and Surgeons of Canada. Analysis of Specialty and Subspecialty Certification of Fellows in Good Standing, July 7, 2000. Ottawa: Royal College of Physicians and Surgeons of Canada, 2000.

11. Paediatric Pulmonary Job Board Job Listings. $<$ http://members.home.net/eisenbej/pedlung/jobboard.htm> (Version current at October 31, 2000).

Please note: Most of these references are in the form of tables, which are available on request from the Royal College of Physicians and Surgeons of Canada. 


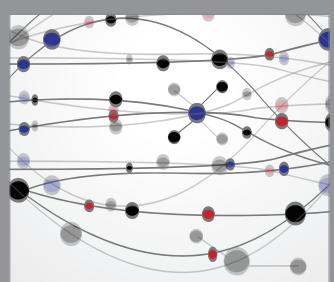

The Scientific World Journal
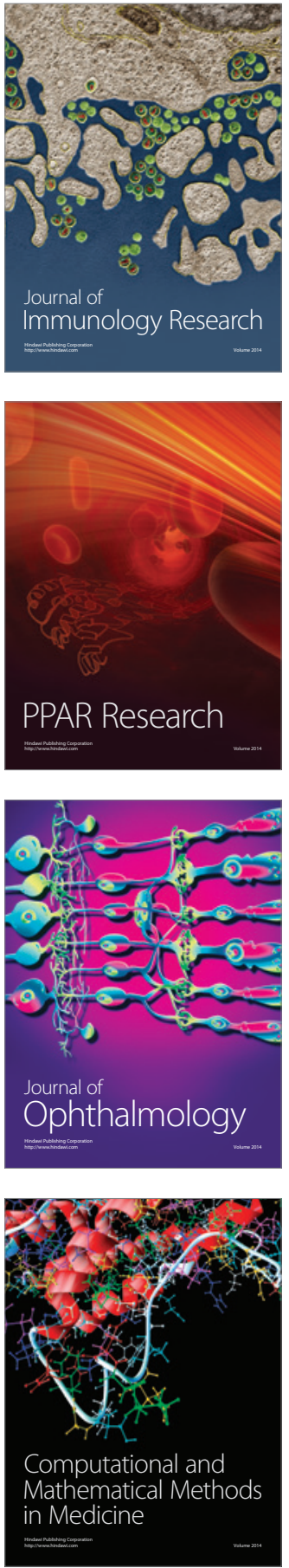

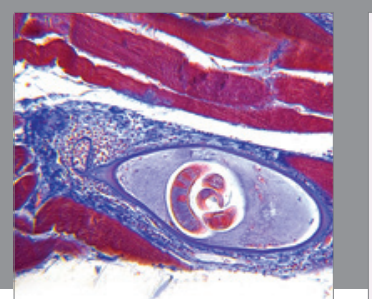

Gastroenterology Research and Practice

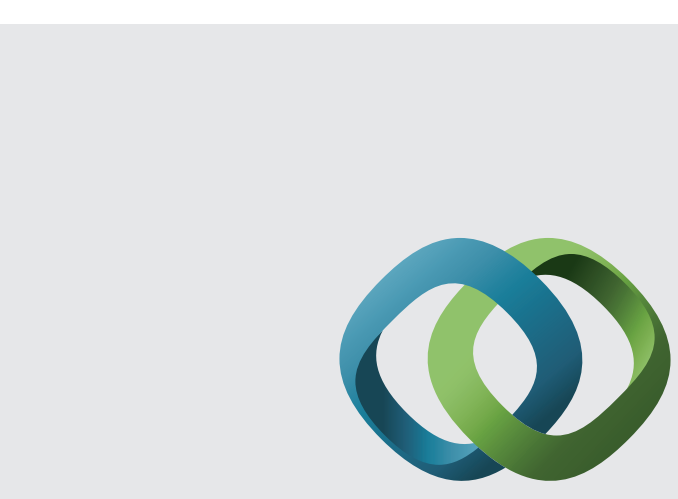

\section{Hindawi}

Submit your manuscripts at

http://www.hindawi.com
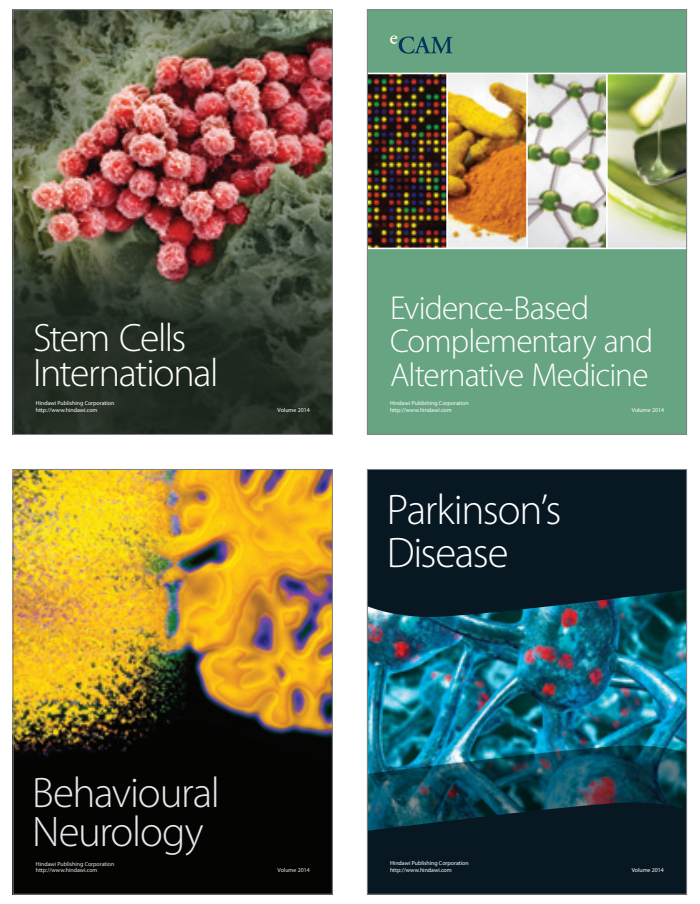
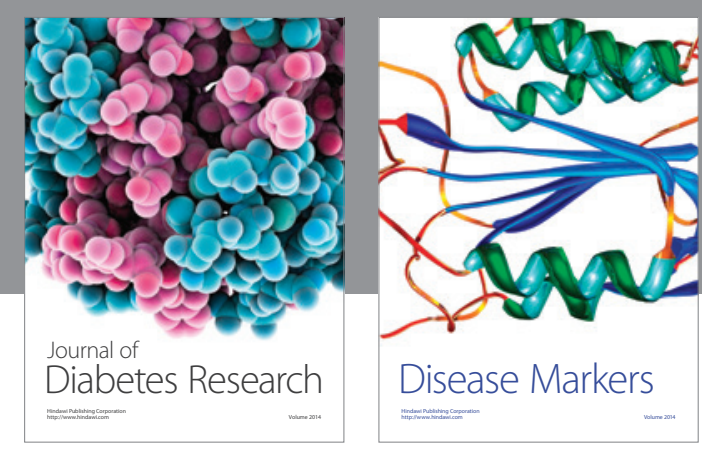

Disease Markers
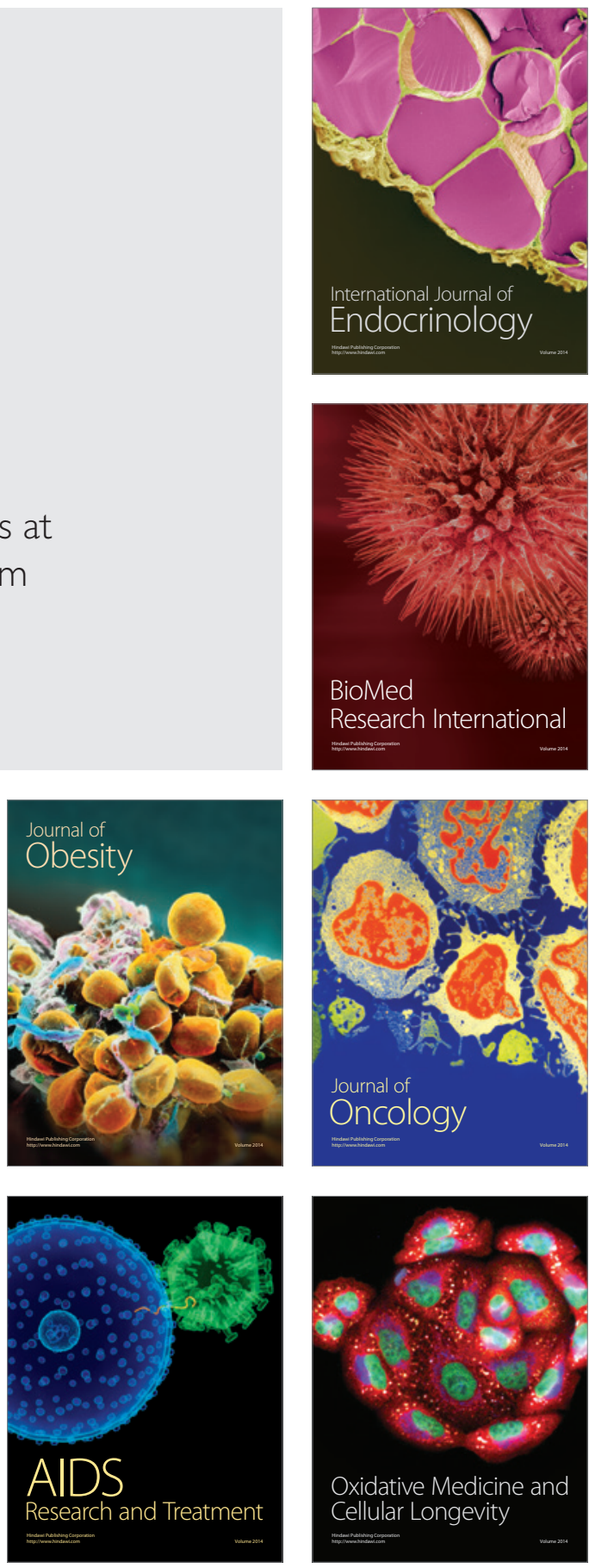